Technical Note

\title{
BIM Supported Surveying and Imaging Combination for Heritage Conservation
}

\author{
Pedro Martín-Lerones ${ }^{1, *(\mathbb{D})}$, David Olmedo ${ }^{1}$, Ana López-Vidal ${ }^{1}$, Jaime Gómez-García-Bermejo ${ }^{2}$ (i) and \\ Eduardo Zalama ${ }^{2}$ (1) \\ 1 CARTIF Technological Center, Boecillo, 47151 Valladolid, Spain; davolm@cartif.es (D.O.); \\ anavid@cartif.es (A.L.-V.) \\ 2 ITAP-DISA, University of Valladolid, 47011 Valladolid, Spain; jaigom@eii.uva.es (J.G.-G.-B.); \\ ezalama@eii.uva.es (E.Z.) \\ * Correspondence: pedler@cartif.es; Tel.: +34-983-548-920
}

Citation: Martín-Lerones, P.; Olmedo, D.; López-Vidal, A.; Gómez-García-Bermejo, J.; Zalama, E. BIM Supported Surveying and Imaging Combination for Heritage Conservation. Remote Sens. 2021, 13, 1584. https://doi.org/10.3390/ rs13081584

Academic Editor: Sander Oude Elberink

Received: 22 March 2021

Accepted: 16 April 2021

Published: 19 April 2021

Publisher's Note: MDPI stays neutral with regard to jurisdictional claims in published maps and institutional affiliations.

Copyright: (C) 2021 by the authors. Licensee MDPI, Basel, Switzerland. This article is an open access article distributed under the terms and conditions of the Creative Commons Attribution (CC BY) license (https:/ / creativecommons.org/licenses/by/ $4.0 /)$.

\begin{abstract}
As the basis for analysis and management of heritage assets, 3D laser scanning and photogrammetric 3D reconstruction have been probed as adequate techniques for point cloud data acquisition. The European Directive 2014/24/EU imposes BIM Level 2 for government centrally procured projects as a collaborative process of producing federated discipline-specific models. Although BIM software resources are intensified and increasingly growing, distinct specifications for heritage (H-BIM) are essential to driving particular processes and tools to efficiency shifting from point clouds to meaningful information ready to be exchanged using non-proprietary formats, such as Industry Foundation Classes (IFC). This paper details a procedure for processing enriched 3D point clouds into the REVIT software package due to its worldwide popularity and how closely it integrates with the BIM concept. The procedure will be additionally supported by a tailored plug-in to make high-quality 3D digital survey datasets usable together with 2D imaging, enhancing the capability to depict contextualized important graphical data to properly planning conservation actions. As a practical example, a 2D/3D enhanced combination is worked to accurately include into a BIM project, the length, orientation, and width of a big crack on the walls of the Castle of Torrelobatón (Spain) as a representative heritage building.
\end{abstract}

Keywords: heritage point cloud; heritage 3D surveying; H-BIM; point cloud-to-BIM

\section{Introduction}

Quality point clouds as raw data are the basis of 3D modeling methodologies. Photogrammetric 3D reconstruction is low cost, flexible, quick, and able to produce truthful models of complex objects in terms of point density and accuracy. On the contrary, when high level details are required, the processing time can become exceptionally long due to the image matching software, which requires powerful hardware resources as well. From this point of view, 3D laser scanning still remains the best technology for providing fullresolution scans in real time. In contrast, large datasets require post-processing to produce a useable output with sophisticated and expensive software [1]. The utilization of one or another technique depends on the study to be carried out, required quality, budget, and time to face it. Hybrid approaches combining photogrammetric reconstruction and laser scanning for 3D documentation can be used for the shape of 3D features to be determined in a flexible and accurate way by means of common 3D data processing tools [2].

Dealing with point cloud data to support Building Information Modeling (BIM) is a popular subject among Architecture, Engineering \& Construction (AEC) professionals [3,4]. Two ways of producing a useful BIM 3D model from point clouds are commonly used in daily practice. Both require manual orientation and may be aided by some semi-automatic functions according to the internal feature-fitting algorithms available to the selected applications. The functions include (1) using specific 3D data processing software to create 
parametric elements on the point clouds to be exportable to BIM packages by compatible formats (i.e., DWG, DXF, DGN, SKP, SAT, 3DM); (2) directly modeling into the BIM software package using special functionalities or complementary applications to handle point clouds. Although the first possibility allows the Computer Aided Design (CAD) to BIM connection, the second one is typically addressed [5] because it allows directly operating into BIM without intermediate conversions upon the full capabilities of the selected package, thereby avoiding the possible loss of information, keeping scale, and preserving the original spatial reference system.

Built heritage plays an essential role in achieving cultural distinction and promoting local identity because of their symbolic, social, economic, and cultural values. Hence, there is a need to adopt digital systems to facilitate the exchange of information to ensure conservation in the best conditions attending to the UNESCO digitization and preservation adoptions [6]. The significant development of BIM could save time, reduce costs, errors and inconsistencies, and enhance the possibility of analyzing information in this regard. This is why the current approaches for built heritage documentation and modeling are to collect, organize, and integrate immovable assets' data into a single graphic-semantic structure using BIM tools. Complementary features need to be developed to enable ordinary BIM systems to meet heritage needs, particularly as a means of preventive conservation under a multidisciplinary approach [7]. It should be pointed out that the complete automation of 3D modeling processes is not currently viable, and needs expert intervention because artificial intelligence has not been yet developed to the extent that it can make architectural assumptions on its own [8-11]. The uniqueness and inherent complexity of the built heritage requires methodological particularizations to shift from point clouds to HeritageBIM (H-BIM).

Different commercial plug-ins for efficiently using rich as-built point cloud data are usually provided by laser scanners makers, mainly for boosting BIM of existing buildings within REVIT as the dominant software among construction engineers, at least in all European countries [12]. This is useful for a wide range of activities, including retrofit design, intervention operations, lifecycle asset management of the building, and virtual visits to the site with a complete view of the captured reality.

The conversion of point clouds into parametrical elements heavily relies on professional knowledge and expertise from practical approaches. Fitting to the increasing demands on H-BIM automation, different case studies on the digital modeling and reconstruction of a representative architectural heritage have recently emerged [13-18]. One illustrative example is the set of fundamental elements of the European medieval defensive architecture, derived from the point cloud of the Castle of Torrelobatón (Valladolid, Spain) [19]. These elements are compliant with the IFC as an open international standardized digital description of the built asset. When possible, they are even linked to the Getty Art \& Architecture Thesaurus (AAT). Using this well-known controlled vocabulary facilitates not only the automation but the consistency in cataloguing of required elements, as well as more efficient retrieval of information in a normalized way. The resulting graphical-semantical linking is multilingual as well.

Further than these advances, viewing and handling 2D/3D combined data is required to support conservation actions based on H-BIM. On one hand, from a hardware point of view, modern equipment often includes calibrated cameras for RGB data capture. However, limited equipment may incorporate other devices such as a calibrated compact add-on infrared camera ready to be controlled and powered directly from some laser scanner models, providing the temperature for every geometrical point in a full panorama. In the view of H-BIM, the sensed temperatures are preserved and spatially traceable as long as the orientation and scale of the scan data remain synchronized. Any other complementary data to support heritage conservation (e.g., additional imaging, master plans, and inspection reports) has to be added separately and, when possible, is quite tricky.

On the other hand, several software providers are trying to elaborate more accurate solutions for combining existing data or simply aggregating successive recording campaigns 
performed by different professionals for enhanced representation and interpretation over time, thereby establishing digital spaces for multidisciplinary collaboration. Distinct examples are bound to specific manufacturers and techniques on texture mapping. Blending photographic, thermal, and other useful images onto 3D data requires a comprehensive solution, but enabling this blending to be imported and handled into a BIM software package needs a specific development, allocating to interconnect the different heritage useful acquisition instruments to BIM, which is the objective of the present work. This is an interoperability issue due to the multiple formats that need to be combined in the IFC standard. Some preliminary results are available [20], but a deep adaptation is required due to the inherent characteristics of the built heritage, which are really far away from the contemporary modular construction of buildings.

The Castle of Torrelobatón (Valladolid, Spain) as a heritage representative demonstrator supports the testing on the matter $\left(41^{\circ} 39^{\prime} 02.7^{\prime \prime} \mathrm{N} 5^{\circ} 01^{\prime} 29.9^{\prime \prime} \mathrm{W}\right)$.

\section{Materials and Methods}

The Castle of Torrelobatón is an outstanding example of the defensive architecture of the Middle Ages in Europe. The Castle also houses the interpretation center of the Revolt of the Communards (1520-1522), considered as the first modern revolution in the history of Europe, before the revolutionary processes in England and France. This makes the Castle of Torrelobatón a unique historical place that needs to be properly conserved.

The 3D point cloud of the Castle of Torrelobatón (local coordinates) was taken combining photogrammetric $3 \mathrm{D}$ reconstruction and $3 \mathrm{D}$ laser scanning. The first technique was aided by a drone DJI Inspire (X3 camera-12 MPx SONY optics) following a helical flying path to acquire the entire envelope (318 full-frame pictures from the ground to a maximum height of $52 \mathrm{~m}, 80 \%$ overlapping). The drone is equipped with a GPS and a 6-axis Inertial Measurement Unit (IMU) that grants the drone hovering and positioning during image acquisition, according to mathematical principles presented in Hosseinyalamdary et al. [21]. A ground-based LIDAR is used instead of an onboard one so that further corrections such as those proposed by Zhang et al. [22] or Wang et al. [23] are not required. Lens calibration is ensured by following the maker's procedure at the very first time the drone is used and at specific service intervals. In-flight, the arms lift to provide the camera with an unobstructed view. A 3-axis gimbal keeps shots steady, and the camera is pointed in the same direction as the quadcopter banks and turns while keeping a self-calibration procedure.

The second technique, i.e., laser scanning, was applied for a single ground-based scan view using a LEICA HDS-3000 on a portion of the NE wall, covering a physical extent of $8.2 \mathrm{~m}$ wide by $17.3 \mathrm{~m}$ high, where better accuracy was needed to monitor a large crack besides recording the reflectivity index for moisture assessment [24]. These devices are traditionally used in the assessment of cracks are contact gauges, where application depends on accessibility and provision of discrete point measurements rather than providing a continuous record of the damage dimension for the whole affected area, as 3D point clouds-based techniques can do.

The respective point cloud acquisition parameters and the accuracy for capturing the shape and appearance of the Castle are given in Table 1.

Table 1. Acquisition parameters of the point cloud for the Castle of Torrelobatón.

\begin{tabular}{ccccc}
\hline Scale Factor & Graphical LOD & Tolerance & Point Cloud Resolution & Accuracy \\
\hline $1: 100$ & $5 \mathrm{~cm}$ & $2.5 \mathrm{~cm}$ & $1.3 \mathrm{~cm}$ & $1.1 \mathrm{~cm}$ \\
$1: 50$ & $2.5 \mathrm{~cm}$ & $1.3 \mathrm{~cm}$ & $0.7 \mathrm{~cm}$ & $0.4 \mathrm{~cm}$ \\
\hline
\end{tabular}

Scale factor: layout standard architectural scales; LOD: Level of Detail; Metric units are expressed in cm for easy understanding; plane-to-cloud modeled accuracy.

PolyWorks universal 3D software platform is used to import and combine the datasets obtained from these two technologies within a single global cloud of 892,453 points saved as a 13.13 MB E57 format file obtained immediately. A standard alignment process using 
3 pairs of equivalent identifiable points between datasets (two window corners and either of the machicolations) and subsequent automatic best-fit is used to do so without the need for topographic support. In-situ measurements such as the dimensions of the entrance door to the Castle serve to correctly scale the photogrammetric reconstruction, additionally oriented on a Google-Earth layer.

A FLUKE Ti32 infrared camera was used for ground-based thermal imaging on the same wall and area covered by laser scanning to help to detect irregularities, hidden elements, and constructive differences if variations between thermal inertia and conductivity regarding the environment were high enough. This camera provides the radiation into IS2 native format images, which are converted to PNG using the manufacturer's software.

Furthermore, a 24.2MP JPG ground-based spectral image into $(400-1000 \mathrm{~nm}$ wavelength: visible-VIS- and Near InfraRed-NIR-ranges) on the equivalent area was externally provided for material identification and characterization.

Point cloud files can be directly imported into REVIT through a wide variety of scan formats using Autodesk RECAP, which automatically triggers the indexing process for the proper use of 3D data within that tool along with advanced editing and viewing options. Indexing time is immediate, running on an i5 microprocessor, 16 MB RAM, Intel UHD integrated graphic card as reference computer capabilities according to the size of the E57 Castle's file imported. This quickly gets point cloud data to work from the world's leading scanner manufacturers formats with simple export options and integration into not only Autodesk's broader portfolio of design software but also into other packages to efficiently join forces across a project in a cooperative and decentralized manner. Hence, point cloud files are converted to the RCS and RCP indexed formats. Every point cloud file has an RCS extension (30.52 MB single file in our case). An RCP format file (Figure 1) is a project file that groups together multiple RCS scan files ( $2 \mathrm{~KB}$ single file in our case).

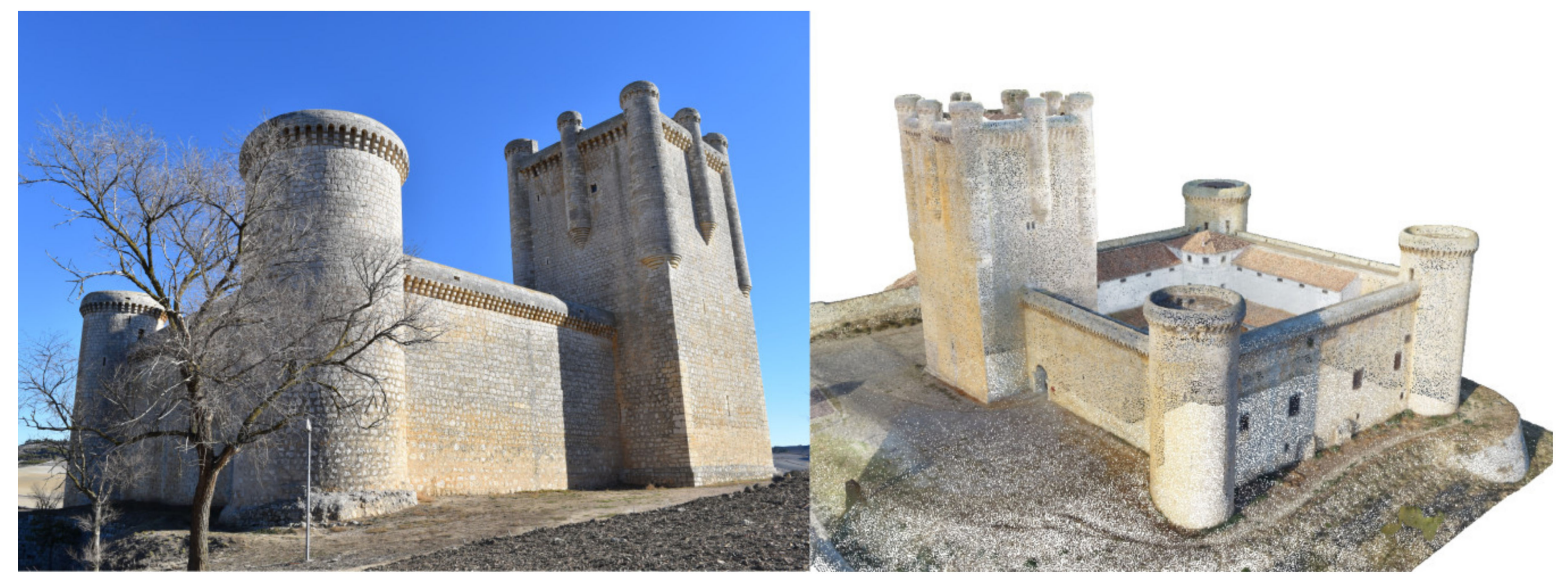

Figure 1. Complete point cloud of the Castle of Torrelobatón into REVIT as RCP.

Although data is meant to be translated between applications using the structured E57 standard file format for 3D imaging data exchange, PLY unstructured point record format is compact and simple, incorporating a file header system that is easy to understand and interpret (it describes an object as a collection of vertices, faces, and other elements, along with properties such as color and normal direction). In addition, the PLY versatility of storing data in either ASCII or binary formats makes it easy to develop tools that manipulate or make calculations on the point cloud. The original point cloud can be converted into a 35.6 MB merged PLY binary format file and added to two 3.4 MB JPG images for texturing.

No BIM software package allows accurately working textured point clouds, so a specific methodology was developed to merge useful digital info for conservation purposes and further handling into the REVIT BIM package to ensure functionality and actual usability using a specifically tailored software tool. Suitable digital information sources 
are 3D point clouds (laser scanning or photogrammetric reconstruction) and 2D imaging (mainly provided by high-res photo cameras and thermal cameras, but also complementary cameras, such as multispectral). Then 3D data: geometry (XYZ coordinates: shape and volume); color (RGB coordinates: real appearance); reflectance ( $\mathrm{L}$ index: reflectivity -only for 3D laser scanning-); and 2D imaging are readily and accurately mapped in a raster-based process with minimal distortion under the same spatial reference.

This leads to the problem of image-to-geometry registration, which consists of determining the parameters of the camera model used to map the image plane onto the point cloud. A pinhole camera model is assumed, so the transformation is described by the projection (intrinsic parameters), as well as the position and orientation of the camera in the space (extrinsic parameters). In this context, the registration can be formalized as an optimization problem in a 7D space: the focal length, the position, and the orientation of the camera. Due to the complexity of finding an optimal solution, MeshLab (an open-source system for processing and editing unstructured 3D data) is used to divide the problem into two sub-problems directly linked to two steps to follow practically: (a) Making a manual initial approximation, and (b) making a best-fit approach running the embedded statistical global method based on mutual information proposed by Dellepiane and Scopigno [25]. Thus, the registration error $(1.2 \mathrm{px})$ is distributed among all the elements of the dataset to refine the alignment of the images on the 3D point cloud while the quality of color projection is improved, especially when dealing with small details. As it is customary in built heritage, the perceptible variations in shape and color of the Castle's walls provide well-defined references to minimize the effect of distortions and low resolution of thermographic and multispectral images for effective texturing.

The resulting enriched 2D/3D point clouds could be saved as many PLY files as mapped images to be managed into REVIT using a custom-made plug-in called the "LOKI tool". Figure 2 describes the process. The LOKI plug-in is programmed in $\mathrm{C}++$ and supported by the Point Cloud Library (PCL) as a standalone, large-scale, open software project for image and point cloud processing. Although this plug-in was originally created for REVIT 2018, it is continuously demanding updates to the evolving versions hand in hand with the surveying and imaging techniques. The LOKI installation pack, including step-by-step instructions, is released as Supplementary Materials to this publication.

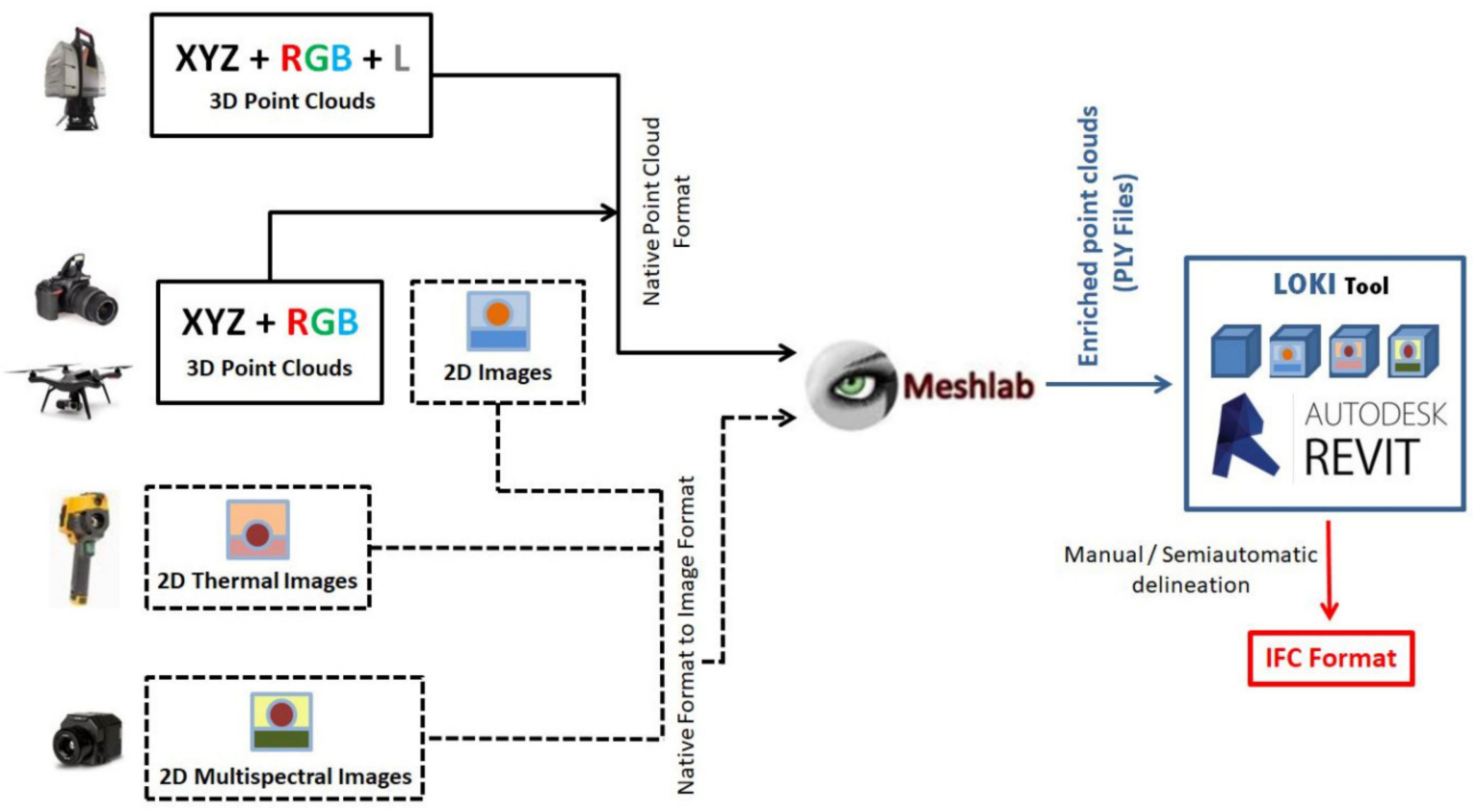

Figure 2. Tailored process for combining 3D data and 2D imaging into REVIT through the LOKI tool for heritage usability. 
The subsequent PLY files serve as 3D templates to extract suitable parametric features for conservation through fully manual/semiautomatic delineation using complementary AEC plug-ins that take advantage of all the REVIT potential. The process is completed by exporting the parametric objects to IFC (when needed) to ensure the interoperability on both building information and geometry throughout the actions to be faced [26,27].

\section{Results}

The described process grants access to precisely reading all required PLY files and displaying them as a layered look in a unique working project into REVIT (RVT format). A specific toolbar is created to allow managing the files following the nomenclature of Table 2.

Table 2. Naming of the LOKI tool for loading and handling files.

Base File (original point cloud): <name $>$.PLY
Reflectance $(\mathrm{L}):<$ name $>$. $<$ REFLECTANCE $>$.PLY
Colour (RGB): $<$ name $>$. $<$ RGB $>$.PLY
Thermal map: $<$ name $>$. $<$ THERMAL $>$.PLY
Other map (i.e., multispectral): $<$ name $>$. $<$ OTHER $>$.PLY

Founded on the consensus of a multidisciplinary team made up of 14 entities from 10 EU countries of the INCEPTION R\&D project, these files cover the full range to assess conservation requirements of the built heritage, which is characterized by complex morphology and non-homogeneous features. Therefore, H-BIM is regularly oriented to create an information repository for documentation and recording activities, condition monitoring, and conservation planning fitted to each specific case. Consequently, the exposed methodology is just exemplified with the analysis of an area of interest of the NE wall on the Castle of Torrelobatón to evaluate operations and maintenance. Monitoring a long, big crack is particularly tasked to the entity in charge of its management to assess the integrity of the structures of the Castle. This task greatly benefited from 3D digitizing techniques for early detection of the origin of the damage and to react appropriately in time.

The user loads the base file, thus LOKI automatically reads all related files located in the same folder (Figure 3). These PLY files serve to analyze the crack, each of them showing a type of complementary data that allow professionals to extract the information required about the damage, and associated impact and extension. The extent of the crack is determined by virtual gauges through the Dynamo Studio functionalities embedded into REVIT, so lengths along the crack are measured and included in the BIM project. The crack is then converted into a parametric entity, which together with the associated lengths are ready to be exported to IFC (Figure 4).

The visualization within REVIT software of the parametrical model of the Castle is shown in Figure 5 to demonstrate the usability of the entire 3D point cloud. The accuracy of the model is $1.65 \mathrm{~cm}$ on average (evaluated by deviation analysis with respect to the point cloud). 


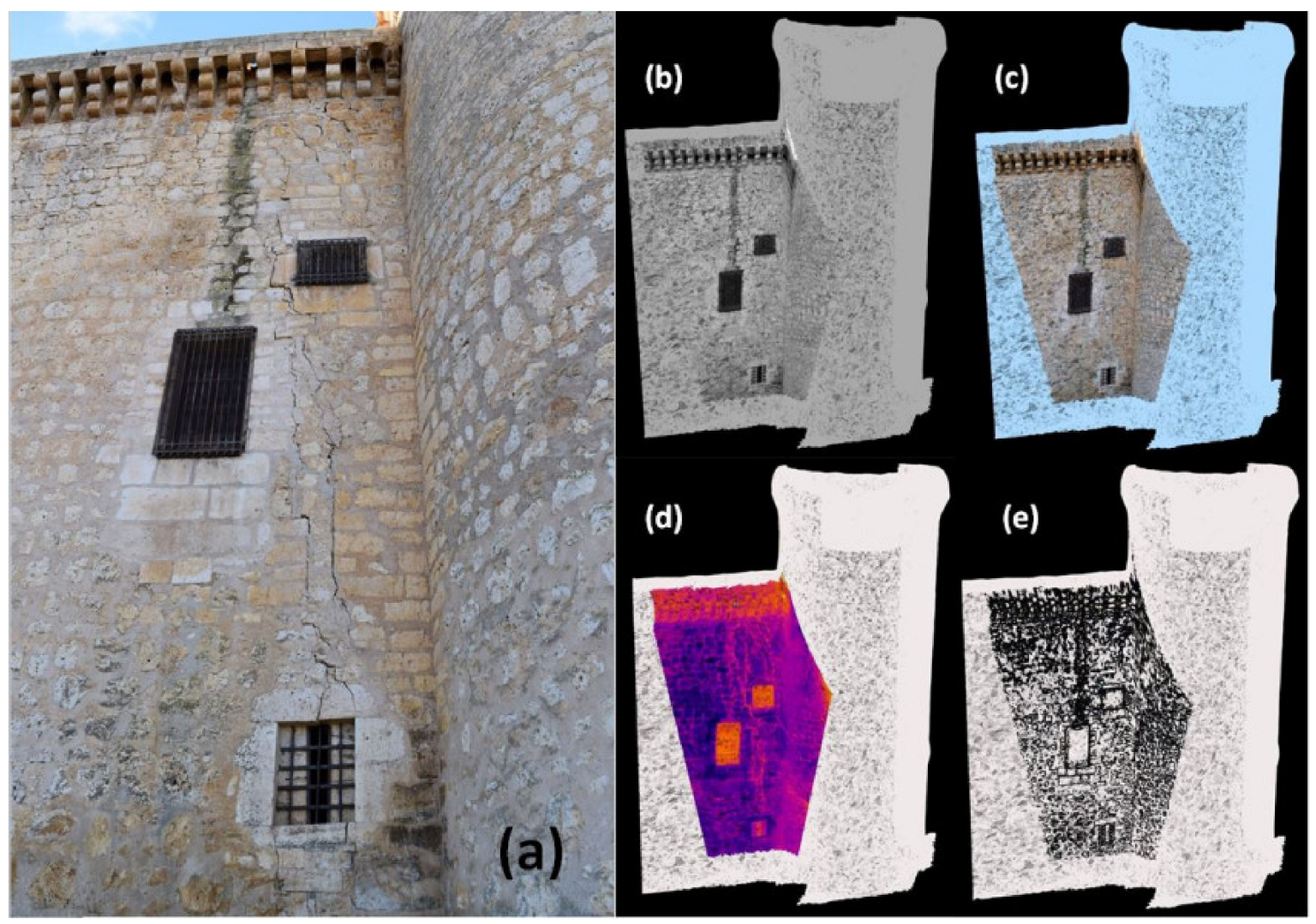

Figure 3. (a) NE wall of the Castle of Torrelobatón; (b) reflectance info; (c) color info; (d) thermal info; (e) multispectral info.
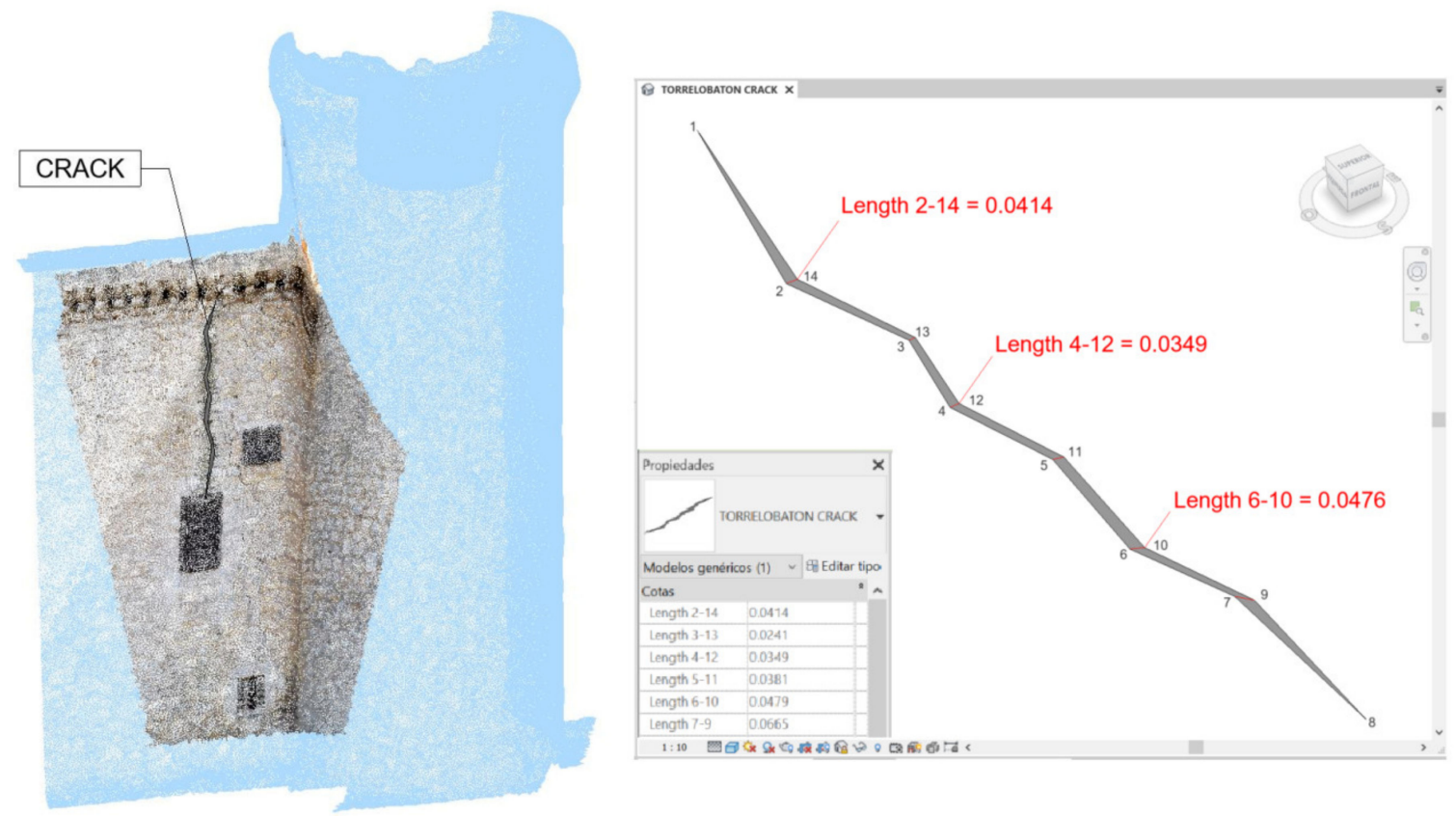

Figure 4. 3D BIM parametrical modeling of the monitored crack, ready to be exported to IFC. 


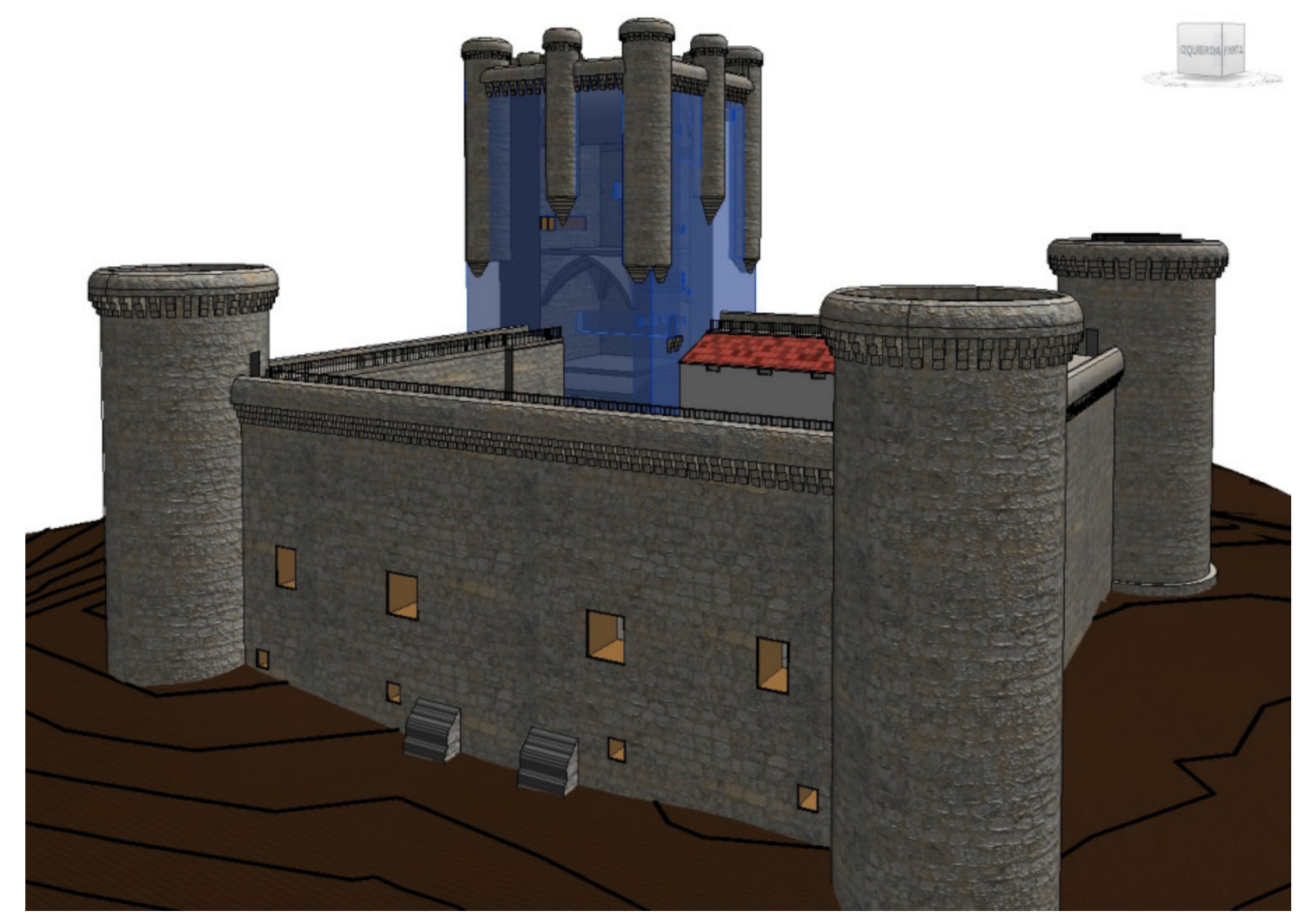

Figure 5. H-BIM parametrical modeling of the Castle of Torrelobatón.

The complete process involving the LOKI tool is described in a self-explanatory video revealing all functions and optimal parameters (https://youtu.be/gtjDbyV-tLs, accessed on 16 April 2021). The process that is followed internally in MeshLab is expressly synthesized in five steps: (i) The image and the point cloud to be merged are imported; (ii) the image is visually superimposed on the point cloud through translations, rotations, and scales guided by know-how; (iii) this process is refined based on image-to-geometry registration for color projection using mutual information, point into which the focal length is estimated; (iv) once aligned, the point cloud is parameterized and textured creating some patches that correspond to the projection of portions of surfaces on the set of registered images; (v) finally, the resulting mesh is exported to PLY format.

\section{Discussion}

Many in the construction field see new buildings as the main application for BIM, but a considerable percentage of projects are part of developments or refurbishments of existing buildings, where heritage is around $13 \%$ of the European building stock. The $3 \mathrm{D}$ point clouds provide outstanding data for analysis and management in the heritage field, however, these data are still transformed and delivered as 2D drawings to AEC professionals across Europe. Several factors drove this at the time: Pure restoration remains the major consideration to ensure heritage sustainability; limited understanding of point cloud data and the capability to handle large datasets; stakeholders' ability and familiarity working with as-built parametric models; hardware and software capabilities to deal with point clouds and models simultaneously.

The European Directive 2014/24/EU [28] requires BIM-based precise processes and tools in due time. This article exemplifies the possibility to interconnect different heritageuseful acquisition instruments to BIM, which is a step beyond mere documentation, easing conservation actions in a normalized way. The scarcity of real applications on the integration of diagnostic 2D imaging and 3D data reinforces the potential of the presented results. However, it is extremely important to keep the associated plug-in updated for usability 
reasons. This is not a technical constraint, but rather a change in the approach to work in a very particular sector such as cultural heritage, which is not prone to innovation.

Crack monitoring is a typical and widespread problem for the built heritage; thus, this paper presents an opportunity for a cost-effective, reliable study aimed at evaluating the feasibility of the 2D/3D enhanced combination into BIM to measure the length, orientation, and width of cracks accurately. This helps to push for H-BIM as the definitive framework for collaborative working across multi-disciplinary teams, making the historic asset information model an invaluable conservation planning instrument throughout their life cycle by improved visualization, analysis, and options appraisals. Hence the scheduling of the difficult conservation work is considerably easier to control, and traditional heritage conservation research methods are overcome because minimal intervention principles are kept and ongoing maintenance is ensured. The use of BIM methods in other aspects of heritage protection is complemented as well (i.e., identification of materials and structural simulation for disaster prevention, which are carried out on static 3D models).

\section{Conclusions}

Heritage projects typically rely on multi-disciplinary collaboration. This means several experts and specialists contribute, exchange, and interpret complex data and information to readily understand the state of conservation of historical buildings according to value and significance. This understanding is crucial to make decisions on conservation actions, but not completely over digital mediums.

Unlike the new-build construction sector, where BIM is increasingly applied at the international level, with scores of relevant publications and online content, H-BIM is still a field of applied research and appears less popular in terms of adoption by heritage professionals despite the obliged compliance with the European Directive 2014/24/EU. Therefore, BIM-supported documentation for the assessment of the built heritage conditions is required, with particular value when fitting to non-invasive data acquisition techniques. This will only be possible by meeting the digitization demands of the heritage conservation sector using tailored developments to make easier and faster the daily work of related professionals.

A practical method to incorporate high-quality 3D digital survey datasets together with 2D imaging regardless of resolution, perspective, and format into a well-known BIM environment is shown. It allows representing the appearance of the existing historic fabric besides the exploration and multifaceted analysis for proper conservation by interconnecting the information from required 2D/3D acquisition instruments to BIM. In consequence heritage, expert knowledge is embedded into an online H-BIM project at a time and semantic enrichment is promoted. The proposed method is proven to allow not only the multidimensional documentation of the state of conservation of the Castle of Torrelobatón as a European representative example on fortification architecture but also the physicochemical damage supervision with accurate $2 \mathrm{D} / 3 \mathrm{D}$ information so that a demonstrative crack can be acted upon with foresight for the reason that structural health is a big issue for the built heritage.

Future promising trends emphasize the improving of methods and tools for automatic conversion of point clouds into H-BIM parametric models, reducing inaccuracies and current severe simplifications on point clouds, as well as extending the IFC standard to solve interoperability issues.

Supplementary Materials: The following are available online at https:/ /www.mdpi.com/article/10 $.3390 /$ rs13081584/s1, Installation Pack 'LOKI Tool'.

Author Contributions: Conceptualization, P.M.-L.; methodology, P.M.-L. and D.O.; software, D.O.; validation, P.M.-L., D.O. and A.L.-V.; formal analysis, J.G.-G.-B. and E.Z.; investigation, P.M.-L., J.G.-G.-B. and E.Z.; resources, P.M.-L., D.O. and A.L.-V.; data curation, P.M.-L., D.O. and A.L.V.; writing-original draft preparation, P.M.-L.; writing—review and editing, J.G.-G.-B. and E.Z.; 
visualization, D.O. and A.L.-V.; supervision, J.G.-G.-B. and E.Z.; funding acquisition, P.M.-L. All authors have read and agreed to the published version of the manuscript.

Funding: The basic research was funded by the European Union's Horizon 2020 program under grant agreement No. 665220 (INCEPTION: www.inception-project.eu, accessed on 16 April 2021). Further fine tuning has been partially funded by "Programa Retos Investigación del Ministerio de Ciencia, Innovación y Universidades (Ref. RTI2018-096652-B-I00)" and "Programa de Apoyo a Proyectos de Investigación de la Junta de Castilla y León (Ref. VA233P18)", co-financed with FEDER funds. The methodology is currently updated and optimized for a business consortium within the Spanish regional project ITEHIS (https:/ /trycsa.com/proyectos-id/, accessed on 16 April 2021).

Informed Consent Statement: Not applicable.

Data Availability Statement: Not applicable.

Acknowledgments: We acknowledge both the practical guidance given by The Spanish Cultural Heritage Institute (IPCE) of the Ministry of Culture and Sports and also the recordings provided by the Directorate General for Cultural Heritage of Castilla y León (Spain).

Conflicts of Interest: The authors declare no conflict of interest.

\section{References}

1. Al Khalil, O. Structure from motion (SfM) photogrammetry as alternative to laser scanning for 3D modelling of historical monuments. Open Sci. 2020, 5. [CrossRef]

2. Alshawabkeh, Y.; El-Khalili, M.; Almasri, E.; Bala'awi, F.; Al-Massarweh, A. Heritage documentation using laser scanner and photogrammetry. The case study of Qasr Al-Abidit, Jordan. Digit. Appl. Archaeol. Cult. Herit. 2020, 16, e00133. [CrossRef]

3. Wang, Q.; Kim, M.K. Applications of 3D point cloud data in the construction industry: A fifteen-year review from 2004 to 2018. Adv. Eng. Inform. 2019, 39, 306-319. [CrossRef]

4. Dinis, F.M.; Sanhudo, L.; Martins, J.P.; Ramos, N.M. Improving project communication in the architecture, engineering and construction industry: Coupling virtual reality and laser scanning. J. Build. Eng. 2020, 30, 101287. [CrossRef]

5. Sanhudo, L.; Ramos, N.M.; Martins, J.P.; Almeida, R.M.; Barreira, E.; Simões, M.L.; Cardoso, V. A framework for in-situ geometric data acquisition using laser scanning for BIM modelling. J. Build. Eng. 2020, 28, 101073. [CrossRef]

6. Von Schorlemer, S. UNESCO and the Challenge of Preserving the Digital Cultural Heritage. In SAACLR, Santander Art and Culture Law Review; Jagiellonian University Press: Kraków, Poland, 2020; pp. 33-64.

7. Antonopoulou, S.; Bryan, P. Historic England: BIM for Heritage: Developing a Historic Building Information Model; Historic England: Swindon, UK, 2017.

8. Tommasi, C.; Achille, C.; Fassi, F. From point cloud to BIM: A modelling challenge in the cultural heritage field. ISPRS Arch. 2016, 41, B5.

9. Arayici, Y.; Counsell, J.; Mahdjoubi, L.; Nagy, G.A.; Hawas, S.; Dweidar, K. (Eds.) Heritage Building Information Modelling; Routledge: New York, NY, USA, 2017.

10. Román Cembranos, J.; Martín Lerones, P.; Llamas Fernández, J.; Zalama Casanova, E.; Gómez García-Bermejo, J. Towards the automatic 3D parametrization of non-planar surfaces from point clouds in HBIM applications. In Proceedings of the 27th CIPA International Symposium “Documenting the Past for a Better Future”, Ávila, Spain, 1-5 September 2019; pp. 1023-1030.

11. Hussein, K.A. State-of-the-art of Historic Building Information Modelling-HBIM Trends in the Built Heritage-Review Paper. DJES 2020, 13, 77-90. [CrossRef]

12. Charef, R.; Emmitt, S.; Alaka, H.; Fouchal, F. Building information modelling adoption in the European Union: An overview. J. Build. Eng. 2019, 25, 100777. [CrossRef]

13. Bruno, S.; De Fino, M.; Fatiguso, F. Historic Building Information Modelling: Performance assessment for diagnosis-aided information modelling and management. Autom. Constr. 2018, 86, 256-276. [CrossRef]

14. Yang, X.; Lu, Y.C.; Murtiyoso, A.; Koehl, M.; Grussenmeyer, P. HBIM modeling from the surface mesh and its extended capability of knowledge representation. ISPRS Int. J. Geo-Inf. 2019, 8, 301. [CrossRef]

15. Abbate, E.; Invernizzi, S.; Spanò, A. HBIM parametric modelling from clouds to perform structural analyses based on finite elements: A case study on a parabolic concrete vault. Appl. Geomat. 2020, 1-18. [CrossRef]

16. Banfi, F. HBIM, 3D drawing and virtual reality for archaeological sites and ancient ruins. Virtual Archaeol. Rev. 2020, 11, 16-33. [CrossRef]

17. Andriasyan, M.; Moyano, J.; Nieto-Julián, J.E.; Antón, D. From Point Cloud Data to Building Information Modelling: An Automatic Parametric Workflow for Heritage. Remote Sens. 2020, 12, 1094. [CrossRef]

18. Pepe, M.; Costantino, D.; Restuccia Garofalo, A. An Efficient Pipeline to Obtain 3D Model for HBIM and Structural Analysis Purposes from 3D Point Clouds. Appl. Sci. 2020, 10, 1235. [CrossRef] 
19. López, F.J.; Martin Lerones, P.; Llamas, J.; Gómez-García-Bermejo, J.; Zalama, E. Linking HBIM graphical and semantic information through the Getty AAT: Practical application to the Castle of Torrelobatón. In Proceedings of the Heri-Tech International Conference, Florence, Italy, 16-18 May 2018.

20. Hernández, J.L.; Martín Lerones, P.; Bonsma, P.; Van Delft, A.; Deighton, R.; Braun, J.-D. An IFC Interoperability Framework for Self-Inspection Process in Buildings. Buildings 2018, 8, 32. [CrossRef]

21. Hosseinyalamdary, S.; Balazadegan, Y.; Toth, C. Tracking 3D Moving Objects Based on GPS/IMU Navigation Solution, Laser Scanner Point Cloud, and GIS Data. ISPRS Int. J. Geo-Inf. 2015, 4, 1301-1316. [CrossRef]

22. Zhang, B.; Zhang, X.; Wei, B.; Qi, C. A Point Cloud Distortion Removing and Mapping Algorithm based on Lidar and IMU UKF Fusion. In Proceedings of the 2019 IEEE/ASME International Conference on Advanced Intelligent Mechatronics (AIM), Hong Kong, China, 8-12 July 2019; pp. 966-971.

23. Wang, K.; Zhou, J.; Zhang, W.; Zhang, B. Mobile LiDAR Scanning System Combined with Canopy Morphology Extracting Methods for Tree Crown Parameters Evaluation in Orchards. Sensors 2021, 21, 339. [CrossRef]

24. Martín Lerones, P.; Olmedo Vélez, D.; Gayubo Rojo, F.; Gómez García-Bermejo, J.; Zalama Casanova, E. Moisture Detection in Heritage Buildings by 3D Laser Scanning. Stud. Conserv. 2016, 61 (Suppl. S1), 46-54. [CrossRef]

25. Dellepiane, M.; Scopigno, R. Global refinement of image-to-geometry registration for color projection. In Proceedings of the Digital Heritage International Congress, Marseille, France, 28 October-1 November 2013; pp. 39-46.

26. Bassier, M.; Vergauwen, M. Topology Reconstruction of BIM Wall Objects from Point Cloud Data. Remote Sens. 2020, 12, 1800. [CrossRef]

27. Soilán, M.; Justo, A.; Sánchez-Rodríguez, A.; Riveiro, B. 3D Point Cloud to BIM: Semi-Automated Framework to Define IFC Alignment Entities from MLS-Acquired LiDAR Data of Highway Roads. Remote Sens. 2020, 12, 2301. [CrossRef]

28. Directive 2014/24/EU of the European Parliament and of the Council of 26 February 2014 on public procurement and repealing Directive 2004/18/EC Text with EEA relevance. Off. J. Eur. Union L 2014, 94, 65-242. 